\title{
Outcomes of patients enrolled in an antiretroviral adherence club with recent viral suppression after experiencing elevated viral loads
}

\begin{tabular}{|c|c|}
\hline $\begin{array}{l}\text { Authors: } \\
\text { Joseph Sharp } \\
\text { Lynne Wilkins } \\
\text { Vivian } \text { Cox }^{3} \\
\text { Carol Cragg } \\
\text { Gilles van Cut } \\
\text { Anna Grimsru }\end{array}$ & $n^{2,3,4}$ (D) \\
\hline \multicolumn{2}{|c|}{$\begin{array}{l}\text { Affiliations: } \\
{ }^{1} \text { Emory University School } \\
\text { of Medicine, Atlanta, } \\
\text { United States }\end{array}$} \\
\hline \multicolumn{2}{|c|}{$\begin{array}{l}{ }^{2} \text { Médecins Sans Frontières, } \\
\text { Cape Town, South Africa }\end{array}$} \\
\hline \multicolumn{2}{|c|}{$\begin{array}{l}{ }^{3} \text { Centre for Infectious Disease } \\
\text { Epidemiology and Research, } \\
\text { School of Public Health and } \\
\text { Family Medicine, University } \\
\text { of Cape Town, Cape Town, } \\
\text { South Africa }\end{array}$} \\
\hline \multicolumn{2}{|c|}{$\begin{array}{l}{ }^{4} \text { International AIDS Society, } \\
\text { Cape Town, South Africa }\end{array}$} \\
\hline \multicolumn{2}{|c|}{$\begin{array}{l}{ }^{5} \text { Provincial Department } \\
\text { of Health, Western Cape, } \\
\text { Cape Town, South Africa }\end{array}$} \\
\hline \multicolumn{2}{|c|}{$\begin{array}{l}\text { Corresponding author: } \\
\text { Joseph Sharp, } \\
\text { joey.sharp@emory.edu }\end{array}$} \\
\hline \multicolumn{2}{|c|}{$\begin{array}{l}\text { Received: } 30 \text { Aug. } 2018 \\
\text { Accepted: } 17 \text { Apr. } 2019 \\
\text { Published: } 11 \text { June } 2019\end{array}$} \\
\hline \multicolumn{2}{|c|}{$\begin{array}{l}\text { How to cite this article: } \\
\text { Sharp J, Wilkinson L, Cox V, } \\
\text { et al. Outcomes of patients } \\
\text { enrolled in an antiretroviral } \\
\text { adherence club with recent } \\
\text { viral suppression after } \\
\text { experiencing elevated } \\
\text { viral loads. S Afr J HIV Med. } \\
2019 ; 20(1) \text {, a905. https://doi. } \\
\text { org/10.4102/sajhivmed. } \\
\text { v20i1.905 }\end{array}$} \\
\hline \multicolumn{2}{|l|}{ Read online: } \\
\hline 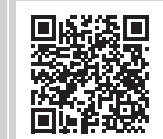 & $\begin{array}{l}\text { Scan this QR } \\
\text { code with your } \\
\text { smart phone or } \\
\text { mobile device } \\
\text { to read online. }\end{array}$ \\
\hline
\end{tabular}

Background: Eligibility for differentiated antiretroviral therapy (ART) delivery models has to date been limited to low-risk stable patients.

Objectives: We examined the outcomes of patients who accessed their care and treatment through an ART adherence club (AC), a differentiated ART delivery model, immediately following receiving support to achieve viral suppression after experiencing elevated viral loads (VLs) at a high-burden ART clinic in Khayelitsha, South Africa.

Methods: Beginning in February 2012, patients with VLs above 400 copies/mL either on firstor second-line regimens received a structured intervention developed for patients at risk of treatment failure. Patients who successfully suppressed either on the same regimen or after regimen switch were offered immediate enrolment in an AC facilitated by a lay community health worker. We conducted a retrospective cohort analysis of patients who enrolled in an AC directly after receiving suppression support. We analysed outcomes (retention in care, retention in AC care and viral rebound) using Kaplan-Meier methods with follow-up from October 2012 to June 2015.

Results: A total of 165 patients were enrolled in an AC following suppression $(81.8 \%$ female, median age 36.2 years). At the closure of the study, 119 patients $(72.0 \%)$ were virally suppressed and 148 patients $(89.0 \%)$ were retained in care. Six, 12 and 18 months after AC enrolment, retention in care was estimated at $98.0 \%, 95.0 \%$ and $89.0 \%$, respectively. Viral suppression was estimated to be maintained by $90.0 \%, 84.0 \%$ and $75.0 \%$ of patients at 6,12 and 18 months after AC enrolment, respectively.

Conclusion: Our findings suggest that patients who struggled to achieve or maintain viral suppression in routine clinic care can have good retention and viral suppression outcomes in ACs, a differentiated ART delivery model, following suppression support.

Keywords: Differentiated care; Retention; Viral suppression; Adherence; High-risk patients; ART delivery.

\section{Introduction}

The introduction of antiretroviral therapy (ART) for the treatment of HIV has led to massive reductions in mortality and slowed the progression of disease and transmission of infection. ${ }^{1,2}$ These reductions are contingent upon strict adherence to ART regimens and long-term retention in care. ${ }^{3,4}$ Treatment programmes throughout the world are both expanding to meet the Joint United Nations Programme on HIV / AIDS (UNAIDS) 90-90-90 targets and continuing to mature, as the first patients initiated in some treatment programmes will soon enter their third decade on ART. ${ }^{5}$ Despite advances in the reduction of the costs of treatment, ${ }^{6}$ the stigma associated with infection ${ }^{7}$ and the need to integrate treatment into daily routines, ${ }^{8,9}$ increasing numbers of patients are interrupting care and experiencing viral rebound. While retention has been consistent between $74 \%$ and $78 \%$ at 12 months from 2005 to $2013,,^{10}$ the number of patients in care globally has increased dramatically from 1.3 million in $2005^{11}$ to over 21.7 million in $2017 . .^{12}$ This trend is evident in South Africa where the treatment programme has grown from just less than 100000 to over 4 million patients, and concurrently, the number of patients interrupting or abandoning care has also increased. ${ }^{13}$ Models of care must adapt to focus on the needs of the growing population that has interrupted ART while supporting quality care for the new patients eligible for ART as countries adopt 'test and start' guidelines. 
Differentiated ART delivery models such as ART adherence clubs (ACs) have been shown to be successful and costeffective in providing treatment, care and support. ${ }^{14,15,16,17}$ These models have traditionally been restricted to clinically stable patients, defined as patients on ART for 12 months or more with two undetectable viral loads (VLs). Differentiated ART delivery models promote adherence by reducing the frequency of visits and time spent in a clinic, allowing for increased peer and lay healthcare worker (LHCW) support and ensuring longer ART supply. ${ }^{18,19,20,21,22,23}$ If such models of ART delivery remain restricted to low-risk stable patients on first-line treatment, the growing cohort of patients struggling with adherence may be left behind, stuck in delivery models that already failed them. Furthermore, it may be the patients who are not stable, those at risk of treatment failure, who stand to gain the most from simplifying their ART refill delivery mechanism. ${ }^{24}$ While differentiated ART delivery models have received widespread attention and have been incorporated into the World Health Organization's treatment guidelines, ${ }^{25}$ they have been restricted to low-risk stable patients. Data on the outcomes of patients at high-risk of experiencing viral rebound who access differentiated ART delivery models do not currently exist. We describe the outcomes of patients referred directly to ACs after viral suppression following specific adherence support.

\section{Research methods and design \\ Study design}

A descriptive retrospective cohort study was undertaken using routine data collected under programmatic conditions at Ubuntu Clinic, Khayelitsha, Western Cape, South Africa, for patients who joined ACs between February 2012 and February 2014 after viral suppression following the risk of treatment failure (ROTF) intervention.

\section{Setting}

The study was conducted at Ubuntu Clinic in Khayelitsha, South Africa. Khayelitsha is a township in Cape Town with a population of approximately half a million people and high rates of HIV and tuberculosis (TB). In 2011, the antenatal HIV prevalence was 34\%..$^{26,27}$ The community is largely poor, with $55 \%$ of the population living in informal housing and $60 \%$ unemployment among working age individuals. ${ }^{28}$ In 2001, Ubuntu Clinic became the first public sector clinic in the country to provide ART; ${ }^{29}$ by March 2017, 10252 patients were retained in ART care at Ubuntu Clinic, with close to 40000 patients in ART care in Khayelitsha sub-district (a sub-district in the Cape Metro district).

\section{Adherence club model and risk of treatment failure intervention}

The AC model has been described in detail previously. ${ }^{15,16,17,18}$ Briefly, in the Western Cape, clients were initially regarded as stable and eligible for the AC model if on ART for 12 months or more with two undetectable VLs and no co-morbidities requiring frequent clinical assessment. In 2015, stability criteria changed to on ART for 6 months or more with a single undetectable VL. Adherence clubs were composed of approximately 30 patients who met with an LHCW five times a year (every 2 months except over year-end holidays when a 4-month ART refill was provided) for a short symptom screen, peer support and distribution of pre-packed ART refills. Some ACs were facility based and met at the Ubuntu Clinic, while others were decentralised to community venues. Adherence club patients had an annual blood draw and an annual clinical consultation as part of their AC visit schedule. If a patient experienced viral rebound (VL > 400) in the AC, failed to attend their AC or became clinically unstable for any reason, the patient was referred back into routine clinic care for ongoing management. The AC model was brought to scale in the Cape Town health district with 40.9\% (62 874 patients) of all ART patients in the district accessing ART care and support through ACs by the end of $2016 .{ }^{30}$ Twenty-fourmonth retention, annual VL completion and viral suppression outcomes $^{31}$ were $89.3 \%, 88.1 \%$ and $97.2 \%$, respectively.

In 2012, the ROTF intervention was piloted at Ubuntu Clinic by Médecins Sans Frontières (MSF) and the Western Cape Department of Health. ${ }^{32,33}$, The Western Cape Department of Health has subsequently adopted the intervention to manage all patients failing or at risk of failing ART with phased implementation in all its Cape Town facilities starting at the end of 2015. The intervention was designed to provide integrated adherence support and clinical management for all patients in routine clinical care with VLs above 400 copies/mL, irrespective of treatment regimen. Patients who experienced a single VL $>400$ copies $/ \mathrm{mL}$ were enrolled in an LHCW support group, while those with two consecutive VLs > 400 copies/mL experienced more intensive counselling with a nurse trained to provide integrated adherence and clinical management. Adherence was managed through structured steps including VL monitoring and switching patients to second-line ART regimens in accordance with national guidelines (two consecutive VLs > 1000 copies/mL).

After suppression (VL $<400$ copies $/ \mathrm{mL}$ ) - whether on first line, after switch to second line or on second line - patients were given the choice to enrol directly into an AC or return to routine clinician-led facility-based care. Patients who suppressed and enrolled in an AC following the ROTF intervention are hereafter referred to as 'high-risk patients' as they were regarded to be at a higher risk of interrupting their treatment again. ${ }^{34,35}$ High-risk patients were enrolled in ACs on a rolling basis, and therefore ACs are composed of both stable and high-risk patients.

\section{Data collection and analysis}

\section{Analysis inclusion and exclusion}

Patients who joined ACs between February 2012 and February 2014 after suppressing in the ROTF intervention were identified retrospectively by comparing the clinic's electronic monitoring records (EMR), which identified patients participating in the ROTF and AC programmes. Additional data were gathered from AC registers on those 
patients who were identified as having participated in both programmes. Patients were excluded if they were enrolled in an AC before the ROTF intervention, enrolled in a family AC (utilised for children and their caregivers), missing from the AC register or confirmed to have never joined an AC (indicating EMR AC participation incorrect), never suppressed after ROTF or if they never had a VL greater than 400 copies/mL (indicating EMR ROTF participation incorrect) (Figure 1). One AC register could not be found, and all patients referred to that $\mathrm{AC}$ were excluded from analysis. This left only high-risk patients confirmed to have joined ACs directly after participation and successful suppression following the ROTF intervention.

\section{Data collection}

Data for each patient in the analysis cohort were collected from patient visit and laboratory data from the EMR and AC registers. Missing VL results were obtained from the National Health Laboratory Service database. Patient clinic folders were consulted for patients whose most recent status was missing from the $\mathrm{AC}$ registers to confirm their current $\mathrm{AC}$ status. Key variables collected included ART regimen, ART start date, ROTF enrolment date, last unsuppressed VL and date, first suppressed VL and date, all VLs and dates after club enrolment and all clinic and club visits after suppression.

\section{Statistical analysis}

Patients entered the analysis on their first AC date (between February 2012 and February 2014) and were followed until March 24, 2015. We assessed three outcomes: retention in care, retention in club care and viral suppression. Retention in care was defined as having contact with the clinic or AC between March 24 and June 21, 2015, with retention in club care defined as attending an AC in the same period. Patients were classified as virally suppressed if their last VL before analysis closure was less than 400 copies/mL. We define viral rebound as an elevated VL above 400 copies / $\mathrm{mL}$ after having achieved viral suppression. Known deaths and transfers contributed retention time until they were censored at the time of death or transfer.

Patient characteristics at enrolment into an AC (gender, age at ART start, age at AC start, year of ART start, treatment regimen) and time from ART initiation to ROTF participation and from ROTF participation to AC enrolment were

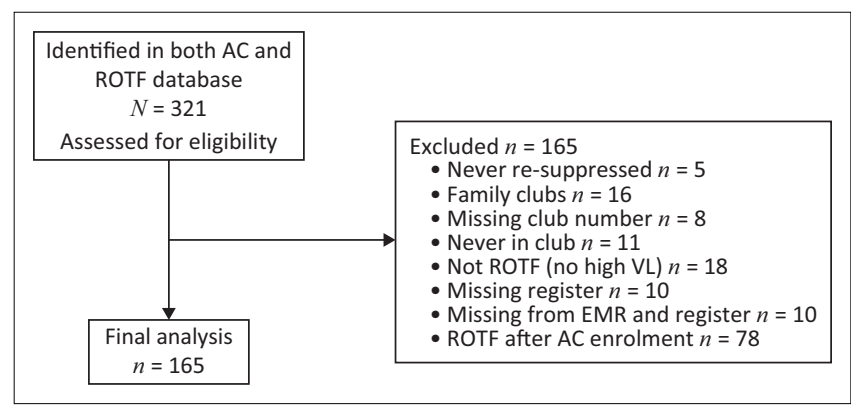

$A C$, adherence club; ROTF, risk of treatment failure; EMR, electronic monitoring records; $\mathrm{VL}$, viral load.

FIGURE 1: Flow chart of analysis inclusion criteria applied to obtain study sample. summarised using medians and interquartile ranges (IQRs) for continuous variables and proportions for categorical variables. Cross-sectional retention outcomes are reported at study closure. Kaplan-Meier methods were used to estimate the survival probabilities of retention, AC retention and viral suppression, and are reported at 3-monthly intervals to 18 months with $95 \%$ confidence intervals (CIs).

Data were analysed using Stata 13.0 software (STATA Corporation, College Station, TX, US).

\section{Ethical consideration}

Because of the nature of the study, individual patient consent was not obtained, consistent with the Declaration of Helsinki. All participants and data were drawn from an ongoing cohort study of routine ART outcomes in Khayelitsha, Cape Town, approved by the Human Research Ethics Committee of the Faculty of Health Sciences at the University of Cape Town (HREC 395/2005). Only routine clinical service data were used and no identifying patient information was entered into the database.

\section{Results \\ Patient characteristics}

From February 2012 to February 2014, 165 high-risk patients who completed the ROTF intervention and suppressed were immediately enrolled in an AC. The cohort was predominantly female $(81.8 \%)$ with a median age at ART start of 31 years (IQR: 28-37). Current treatment regimens were available for 133 patients, and of those $105(79 \%)$ were on second-line therapy (Table 1) at the time of AC enrolment. The median time from ART initiation to enrolment in the ROTF intervention was 3.4 years (IQR: 2.1-5.5), and the median time from ROTF intervention to AC enrolment was 1.2 years (IQR: 1.0-1.5).

\section{Cross-sectional outcomes}

During the study period, two patients (1.2\%) died, 15 (7.8\%) were lost to follow-up and $40(24.0 \%)$ experienced viral rebound. At the closure of the study, 148 patients (89.0\%) were retained in care and 119 patients $(72.0 \%)$ were virally suppressed. When stratified by known ART regimen, 26 patients $(93.0 \%)$ on first line and 97 patients $(92.0 \%)$ on second line were retained in care, while 20 patients $(71.0 \%)$ on first line and 83 patients $(79.0 \%)$ on second line were virally suppressed.

\section{Time to event outcomes}

Retention in care was estimated to be $98.8 \%$ (95\% CI, 94.4-99.4), 94.8\% (95\% CI, 89.8-97.4) and 89.3\% (95\% CI, 81.8-93.8) at 6, 12 and 18 months after AC enrolment, respectively (Table 2, Figure 2a). Retention in AC care was estimated to be $98.2 \%$ (95\% CI, 94.4-99.4), 92.0\% (95\% CI, 86.3-95.4) and $80.5 \%$ (95\% CI, 72.0-86.6) over the same time periods (Table 2, Figure $2 b$ ). Eighteen months after enrolment 
in ACs, $90 \%$ of patients retained in clinic care were still in ACs. Viral suppression was estimated to be $90.0 \%$ (95\% CI, 84.1-93.7), 83.9\% (95\% CI, 76.8-88.9) and 75.0\% (95\% CI, 66.0-81.9) at 6, 12 and 18 months after AC enrolment, respectively (Table 2, Figure 2c).

\section{Discussion}

Patients who had previously had elevated VLs had good treatment outcomes following supported viral suppression and direct referral to ACs, a differentiated ART delivery model. Despite having had recent elevated VL, $75 \%$ of patients who joined ACs after undergoing a ROTF intervention were estimated to maintain viral suppression 18 months after joining the AC. Eighteen months after AC enrolment, retention in care was estimated at $89 \%$, and $90 \%$ of patients retained in care were still in ACs. Care was differentiated in the intensified

TABLE 1: Description of risk of treatment failure patients who suppressed and were referred to an adherence club.

\begin{tabular}{|c|c|c|c|c|}
\hline \multirow[t]{2}{*}{ Characteristic } & \multicolumn{4}{|c|}{$N=165$} \\
\hline & $N$ & $\%$ & Median & IQR \\
\hline \multicolumn{5}{|l|}{ Gender } \\
\hline Males & 30 & 18.2 & - & - \\
\hline Females & 135 & 81.8 & - & - \\
\hline Age ART start & - & - & 30.7 & $27.6-37.1$ \\
\hline \multicolumn{5}{|l|}{ Age } \\
\hline $16-19$ & 3 & 1.8 & - & - \\
\hline $20-24$ & 16 & 9.7 & - & - \\
\hline $25-34$ & 89 & 54.9 & - & - \\
\hline $35-44$ & 45 & 27.3 & - & - \\
\hline $45+$ & 12 & 7.3 & - & - \\
\hline Age ART start & - & - & 36.2 & $32.2-32.4$ \\
\hline \multicolumn{5}{|l|}{ Categorical } \\
\hline $16-19$ & 0 & 0.0 & - & - \\
\hline $20-24$ & 1 & 0.6 & - & - \\
\hline $25-34$ & 66 & 40.0 & - & - \\
\hline $35-44$ & 69 & 41.8 & - & - \\
\hline $45+$ & 29 & 17.6 & - & - \\
\hline \multicolumn{5}{|l|}{ Year of ART start } \\
\hline 2002-2005 & 27 & 16.4 & - & - \\
\hline 2006-2008 & 56 & 33.9 & - & - \\
\hline 2009-2010 & 51 & 30.9 & - & - \\
\hline 2011-2013 & 31 & 18.8 & - & - \\
\hline \multicolumn{5}{|l|}{ Regimen at $\mathrm{AC}$ start } \\
\hline First line & 28 & 21.1 & - & \\
\hline Second line & 105 & 79.0 & - & \\
\hline Median time from ART start to ROTF, years & - & - & 3.4 & $2.1-5.5$ \\
\hline Median time from ART start to AC start, years & - & - & 4.7 & $3.4-7.2$ \\
\hline Median time from ROTF start to AC start, years & - & - & 1.2 & $1.0-1.5$ \\
\hline
\end{tabular}

ART, antiretroviral therapy; IQR, interquartile range; AC, adherence club; ROTF, risk of treatment failure.
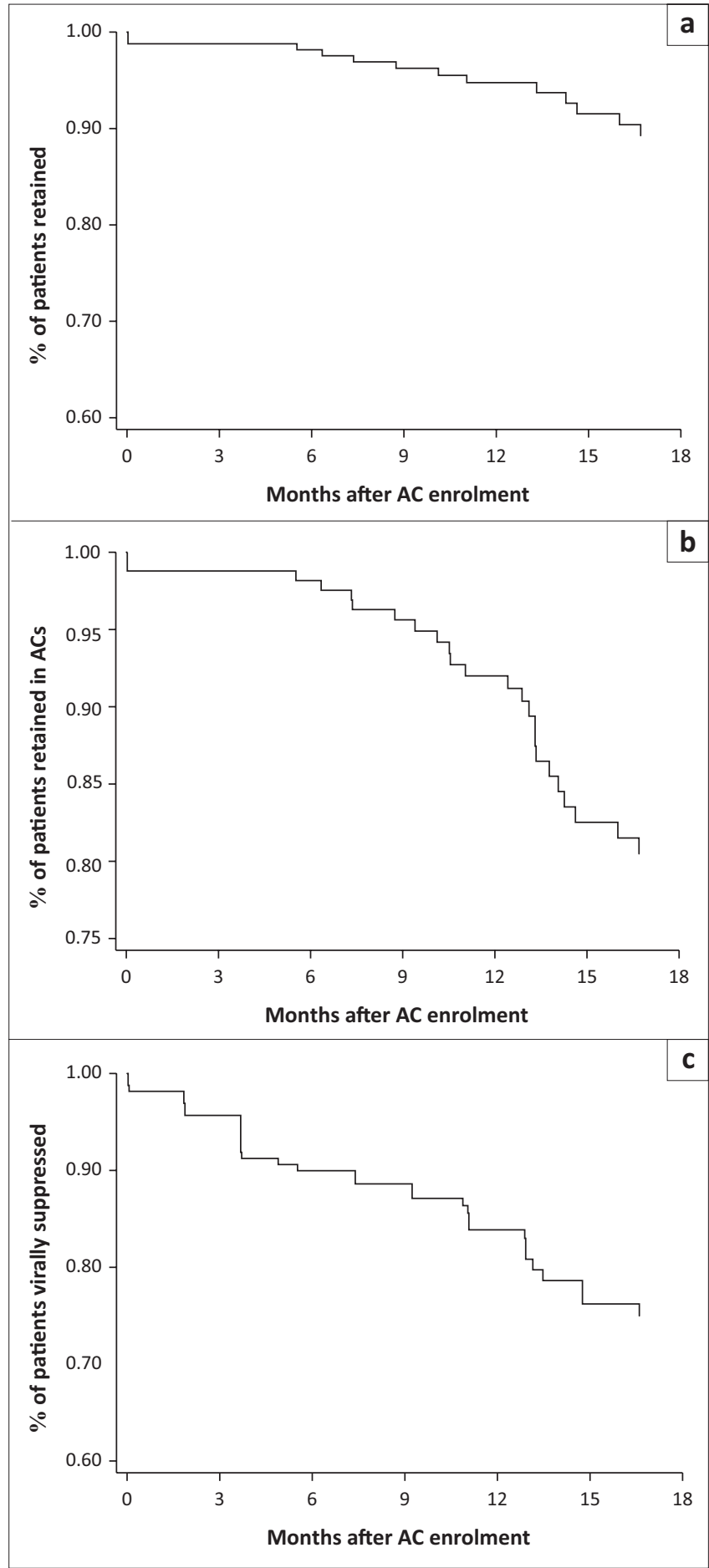

AC, adherence club.

FIGURE 2: Retention in care (a), retention in adherence club care (b) and viral suppression (c) over the first 18 months in adherence clubs immediately after viral suppression and referral to an adherence club.

TABLE 2: Kaplan-Meier estimates of retention in care, retention in adherence club care and viral suppression by duration of follow-up after first AC meeting.

\begin{tabular}{|c|c|c|c|c|c|c|c|c|c|c|c|}
\hline \multirow{2}{*}{$\begin{array}{l}\text { Duration of } \\
\text { follow-up }\end{array}$} & \multirow[t]{2}{*}{$n$} & \multirow[t]{2}{*}{$\%$} & \multicolumn{3}{|c|}{ Retention in care } & \multicolumn{3}{|c|}{ Retention in $\mathrm{AC}$ care } & \multicolumn{3}{|c|}{ Viral suppression } \\
\hline & & & Events & $\%$ & $95 \% \mathrm{Cl}$ & Events & $\%$ & $95 \% \mathrm{Cl}$ & Events & $\%$ & $95 \% \mathrm{Cl}$ \\
\hline 3 months & 160 & 97.0 & 2 & 98.8 & $95.2-99.7$ & 2 & 98.8 & $95.2-99.7$ & 7 & 95.7 & $91.1-97.9$ \\
\hline 6 months & 159 & 96.3 & 1 & 98.2 & $94.4-99.4$ & 1 & 98.2 & 94.4-99.4 & 9 & 90.0 & $84.1-93.7$ \\
\hline 9 months & 145 & 87.9 & 3 & 96.2 & $91.8-98.3$ & 4 & 95.6 & $91.0-97.9$ & 2 & 88.6 & $82.5-92.7$ \\
\hline 12 months & 127 & 77.0 & 2 & 94.8 & $89.8-97.4$ & 5 & 92.0 & $86.3-95.4$ & 6 & 83.9 & $76.8-88.9$ \\
\hline 15 months & 82 & 49.7 & 3 & 91.5 & $84.9-95.3$ & 10 & 82.5 & $74.4-88.3$ & 7 & 76.2 & $67.4-82.9$ \\
\hline 18 months & 80 & 48.5 & 2 & 89.3 & $81.8-93.8$ & 2 & 80.5 & $72.0-86.6$ & 1 & 75.0 & $66.0-81.9$ \\
\hline
\end{tabular}

$\mathrm{AC}$, adherence club; $\mathrm{Cl}$, confidence interval. 
management intervention to target patients failing treatment and in the ART delivery model provided immediately after suppression. To date there is limited evidence on the outcomes of high-risk patients in ART delivery models differentiated for stable patients.

We observed retention and viral suppression outcomes matching or exceeding those of retention benchmarks and meta-analyses from sub-Saharan Africa through 18 months of follow-up. Retention in sub-Saharan Africa was estimated to be $81 \%$ at 12 months, ${ }^{10}$ significantly less than the $94.8 \%$ retention in this cohort of recently suppressed patients. While we report 12-month retention from AC enrolment, not ART initiation, this remains significant. Twelve-month retention is only slightly lower than the 12-month $97.0 \%$ retention observed in stable patients in ACs at the same clinic $^{15}$ and the $99.0 \%$ retention observed in stable patients in a similar community $\mathrm{AC}$ cohort $^{36}$ and the 12-month retention in ACs across the Cape Metro. ${ }^{31}$ In a 2015 systematic review of VL suppression, 12-month suppression in sub-Saharan Africa was estimated to be $64.2 \%{ }^{37}$ We observed $83.9 \%$ viral suppression at 12 months after AC enrolment. These outcomes also compare well to those of patients switched to second-line regimens. Analysis of a cohort in Durban, South Africa, found 25.0\% virological failure every 6 months after switching to second-line regimens. ${ }^{38}$ In a European cohort of treatment-experienced patients who recently achieved viral suppression, 31.0\% of patients experienced viral rebound within 1 year. ${ }^{35}$ Considering $100.0 \%$ of the study cohort experienced recent elevated VLs and 79.0\% had either recently been switched to a second-line regimen within the ROTF intervention or entered ROTF on a second-line regimen, our results are promising.

Ninety per cent of patients retained in care after 18 months were still receiving their care in ACs, suggesting a high level of satisfaction with the service delivery model. This result is important because patient satisfaction is a strong predictor of adherence to ART regimens. ${ }^{39}$ While patients on ART experience elevated VLs (including viral rebound) for a variety of reasons, the single largest predictor is sub-

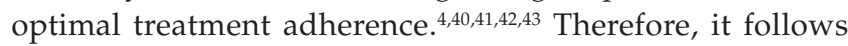
that patients have better outcomes in models that better fit their lives. The AC model may support patients struggling with adherence in routine care by reducing or removing barriers to adherence.

In addition to the differentiated nature of the ACs, the model was also differentiated from routine care, providing more intensified integrated adherence and clinical care through the ROTF intervention to meet the needs of patients as they attempted to achieve viral suppression after elevated VLs and remain in care. This model of VLinformed differentiated care has been shown to be effective and cost-efficient in supporting patients who experience elevated VLs in routine care. ${ }^{44}$ In other words, it is possible that both the intense support in achieving suppression through the ROTF and simplifying ongoing access to care and treatment, with peer support, through the AC model immediately after suppression could be responsible for the positive outcomes.

These results should be viewed in light of a number of limitations. Firstly, a control group was not obtained, making comparison of these results difficult. Because of the retrospective nature of the study and the ability of patients to self-select into AC care or routine clinic care after ROTF, any control group chosen would be biased. We chose to compare the outcomes to broader benchmark goals for all ART programmes. Importantly, our analysis begins at AC enrolment and not ART start. Because the largest drop in retention occurs immediately after ART start, care must be taken when comparing these results to those of newly enrolled patients. Secondly, tracing of patients lost to followup to identify undocumented transfers was not completed. However, any bias this limitation created would serve to reduce observed retention. Thirdly, patients were given the choice to join an AC or return to routine clinic care after completing the ROTF intervention. It is therefore possible that only the motivated patients joined ACs, and our results are not representative of all patients who have experienced an elevated VL. This scenario is unlikely because fewer than $10.0 \%$ of patients chose to return to routine care after achieving suppression. Regardless, by allowing patients to self-select into care models, the probability that they will find a model of care that suits their life, and thus maintain adherence, increases. Fourthly, it is possible that transmitted resistance to first-line regimens was responsible for the positive response in patients switched to second line. This would only account for a small proportion of patients given the relative infrequency of transmitted resistance in South Africa $^{45}$ and the extensive evidence indicating that nonadherence is the primary cause of an elevated VL. ${ }^{32,46}$ It is also possible that patients switched to second-line therapy had positive viral suppression results despite continued poor adherence because of a switching effect. ${ }^{47}$ However, this effect is thought to be minimal as most patients who fail second-line treatment after switching do so within the first 2 years and the outcome would be seen within our follow-up period. ${ }^{48}$ Unfortunately, we are unable to differentiate the patients who entered the ROTF intervention on second-line regimens from those who were switched to second line during the intervention and are susceptible to this switching effect. In addition, because of the limited number of patients, there was insufficient power to analyse associations between outcomes and patient demographics. An attempt was made to include all patients who participated in both ROTF and ACs by cross-referencing both databases; however, it is possible that patients were missed in our sampling approach. In addition, data were collected from routine clinical databases and thus may be subject to data quality error. Finally, it is possible that the exclusion criteria that were applied biased the results towards increased retention and viral suppression. This possibility was minimised by crosschecking multiple data sources and excluding the entire 
AC when information was missing for a selective subset of patients in that AC. Despite these limitations, we find these results promising in introducing the idea that patients who experienced a recent elevated VL can have positive outcomes if care is differentiated to meet their specific needs at a particular time point in their treatment pathway.

\section{Conclusion}

Further research is needed to fully understand how less intense, differentiated ART delivery models can collectively support the heterogeneous population of patients currently ineligible for these models. We recommend both smallscale implementation in diverse contexts to assess the generalisability of our findings and randomised control trials to directly compare the outcomes of patients experiencing elevated VLs recently suppressed or resuppressed immediately accessing a simplified ART delivery model versus routine care. Tests of association should be employed to determine the populations who could most benefit. Finally, retention in AC care had its sharpest decline between 12 and 18 months, and longer term follow-up is needed to determine if differentiated ART delivery models can support patient retention over the long run. In summary, criteria for differentiation must continue to be re-evaluated. Using the criteria of proven 'stability' may exclude those who have the most to gain from streamlining access to ART, including those who have recently suppressed.

In conclusion, our findings suggest that patients who struggled to achieve or maintain viral suppression in routine clinic care can have good retention and viral suppression outcomes in differentiated ART delivery models, such as ACs, immediately following suppression support. These models may remove health system barriers imposed by clinician-led facility-based models. Further studies are required to evaluate both retention and viral suppression benefits of expanding access to differentiated ART delivery models to patients who have struggled with adherence.

\section{Acknowledgements}

The authors thank all the staff at Ubuntu Clinic and Khayelitsha and Eastern sub-structure for their ongoing dedication to their patients demonstrated through their continued support for piloting models of care that better suit the needs of their patients. The authors would also like to thank the MSF ROTF and AC nurses and counsellors who mentor and support their colleagues at Ubuntu Clinic.

\section{Competing interests}

The authors declare that they have no financial or personal relationship(s) that may have inappropriately influenced them in writing this article.

\section{Authors' contributions}

J.S. was responsible for the writing of the article, with statistical analysis completed by J.S. and A.G. J.S. and
L.W. collected the data for analysis. J.S., L.W., C.C., G.v.C. and A.G. contributed to the plan of the analysis and interpretation of the data. L.W. and V.C. developed the ROTF to AC protocol. All authors commented on drafts of the article and approved the final version to be published.

\section{References}

1. Johnson L, Mossong J, Dorrington E, et al. Life expectancies of South African adults starting antiretroviral treatment: Collaborative analysis of cohort studies. PLoS Med. 2013;10(4):e1001418. https://doi.org/10.1371/journal.pmed.1001418

2. Cohen MS, Chen YQ, McCauley M, et al. Prevention of HIV-1 infection with early antiretroviral therapy. N Engl J Med. 2011;365(6):493-505. https://doi.org/ antiretroviral therapy. N
$10.1056 /$ NEJMoa1105243

3. Mills EJ, Nachega JB, Buchan I, et al. Adherence to antiretroviral therapy in subSaharan Africa and North America: A meta-analysis. JAMA. 2006;296(6):679-690. https://doi.org/10.1001/jama.296.6.679

4. Nachega JB, Marconi VC, Van Zyl GU, et al. HIV treatment adherence, drug resistance, virologic failure: Evolving concepts. Infect Disord Drug Targets. 2011;11(2):167-174. https://doi.org/10.2174/187152611795589663

5. UNAIDS. 90-90-90: An ambitious treatment target to help end the AIDS epidemic Geneva: UNAIDS; 2014.

6. Tse W, Yang W, Haung W. A narrative review of cost-effectiveness analysis of people living with HIV treated with HAART: From interventions to outcomes. Clinicoecon Outcomes Res. 2015;7:431-439. https://doi.org/10.2147/CEOR. S85535

7. Madi D, Gupta P. Achappa B, et al. HIV status disclosure among people living with $\mathrm{HIV}$ in the era of combination antiretroviral therapy (cART). J Clin Diagn Res. 2015;9(8):14-16. https://doi.org/10.7860/JCDR/2015/12511.6373

8. Bemelmans M, Baert S, Goemaere E, et al. Community-supported models of care for people on HIV treatment in sub-Saharan Africa. Trop Med Int Health. 2014;19(8):968-977. https://doi.org/10.1111/tmi.12332

9. Okoboi S, Ding E, Persuad S, et al. Community-based ART distribution system can effectively facilitate long-term program retention and low-rates of death and virologic failure in rural Uganda. AIDS Red Ther. 2015;12(37)e1-e9. https://doi. org/10.1186/s12981-015-0077-4

10. Fox M, Sydney R. Retention of adult patients on antiretroviral therapy in low- and middle-income countries: Systematic review and meta-analysis 2008-2013. J Acquir Immune Defic Syndr. 2015;16(1):98-108. https://doi.org/10.1097/QAI 0000000000000553

11. UNAIDS. 2006 report on the global AIDS epidemic. Geneva: UNAIDS; 2006.

12. UNAIDS. Global HIV \& AIDS statistics - 2018 fact sheet. Geneva: UNAIDS; 2018.

13. Kaplan SR, Oosthuizen $C$, Stinson $K$, et al. Contemporary disengagement from antiretroviral therapy in Khayelitsha, South Africa: A cohort study. PLoS Med. 2017;14(11):e1002407. https://doi.org/10.1371/journal.pmed.1002407

14. Decroo T, Rasschaert F, Telfer B, Remartinez D, Laga M, Ford N. Community-based antiretroviral therapy programs can overcome barriers to retention of patients and decongest health services in sub-Saharan Africa: A systematic review. Int Health. 2013;5(3):169-179. https://doi.org/10.1093/inthealth/iht016

15. Luque-Fernandez MA, Van Cutsem G, Goemaere E, et al. Effectiveness of patient adherence groups as a model of care for stable patients on antiretroviral therapy in Khayelitsha, Cape Town, South Africa. PLoS One. 2013;8(2):e56088. https://doi. org/10.1371/journal.pone.0056088

16. Grimsrud A, Lesosky M, Kalombo C, Bekker L G, Myer L. Community-based adherence clubs for the management of stable antiretroviral therapy patients in Cape Town, South Africa: A cohort study. J Acquir Immune Defic Syndr. 2015;71(1):16-23. https://doi.org/10.1097/QAI.0000000000000863

17. Bango F, Ashmore J, Wilkinson L, Van Cutsem G, Cleary S. Adherence clubs for longterm provision of antiretroviral therapy: Cost-effectiveness and access analysis from Khayelitsha, South Africa.
doi.org/10.1111/tmi.12736

18. Wilkinson L. ART adherence clubs: A long-term retention strategy for clinically stable patients receiving antiretroviral therapy. South Afr J HIV Med. 2013;14(2): 48-50. https://doi.org/10.4102/sajhivmed.v14i2.77

19. Auld AF, Shiraishi RW, Couto A, et al. A decade of antiretroviral therapy scale-up in Mozambique: Evaluation of outcome trends and new models of service delivery among more than 300,000 patients enrolled during 2004-2013. J Acquir Immune Defic Syndr. 2016;73(2):e11-e22. https://doi.org/10.1097/QAl.0000000000001137

20. Decroo T, Koole O, Remartinez D, et al. Four-year retention and risk factors for attrition among members of community ART groups in Tete, Mozambique. Trop Med Int Health. 2014;19(5):514-521. https://doi.org/10.1111/tmi.12278

21. Wringe A, Cawley C, Szumilin E, et al. Retention in care among clinically stable antiretroviral therapy patients following a six-monthly clinical consultation schedule: findings from a cohort study in rural Malawi. J Int AIDS Soc. 2018;21(11) e25207. https://doi.org/10.1002/jia2.25207

22. Mody A, Roy M, Sikombe K, et al. Improved retention with six month clinic return intervals for stable HIV-infected patients in Zambia. Clin Infect Dis. 2017;66(2): 237-243. https://doi.org/10.1093/cid/cix756

23. Vogt F, Kalenga L, Lukela J, et al. Decentralizing ART supply for stable HIV patients to community-based distribution centers: Program outcomes from an urban context in Kinshasa, DRC. J Acquir Immune Defic Syndr. 2017;74(3):326-331. https://doi.org/10.1097/QAl.0000000000001215 
24. Grimsrud A, Bygrave H, Doherty M, et al. Reimagining HIV service delivery: The role of differentiated care from prevention to suppression. J Int AIDS Soc 2016;19(1):21484. https://doi.org/10.7448/IAS.19.1.21484

25. World Health Organization. Consolidated guidelines on the use of antiretroviral drugs for treating and preventing HIV infection: Recommendations for a public health approach. 2nd ed. Geneva: WHO; 2016.

26. Provincial Health Department of the Western Cape. HIV antenatal survey. 2012 Cape Town: Provincial Health Department of the Western Cape; 2013.

27. Stinson K, Goemaere E, Coetzee D, et al. Cohort profile: The Khayelitsha antiretroviral programme, Cape Town, South Africa. Int J Epidemiol. 2017;46(2):e21. antiretroviral programme, Cape Town,
https://doi.org/10.1093/ije/dyw057

28. Western Cape Government. City of Cape Town 2016. Socioeconomic profile [homepage on the Internet]. Cape Town: City of Cape Town; 2016. Available from: https://www.westerncape.gov.za/assets/departments/treasury/Documents/ Socio-economic-profiles/2016/City-of-Cape-Town/city_of_cape_town_2016 socio-economic_profile_sep-lg.pdf.

29. Coetzeea D, Hildebranda K, Boullea A, et al. Outcomes after two years of providing antiretroviral treatment in Khayelitsha, South Africa. AIDS. 2004;18(6):887-895. https://doi.org/10.1097/00002030-200404090-00006

30. Wilkinson L, Harley B, Sharp J, et al. Expansion of the adherence club model for stable antiretroviral therapy patients in the Cape Metro, South Africa 2011-2015. Trop Med Int Health. 2016;21(6):743-749. https://doi.org/10.1111/tmi.12699

31. Tsondai P, Wilkinson L, Grimsrud A, Mdlalo P, Ullauri A, Boulle A. High rates of retention and viral suppression in the scale-up of antiretroviral therapy adherence clubs in Cape Town, South Africa. JIAS. 2017;20(S4):21649. https://doi.org/ 10.7448/IAS.20.5.21649

32. Garone D, Conradie K, Patten G, et al. High rate of virological re-suppression among patients failing second-line antiretroviral therapy following enhanced among patients failing second-line antiretroviral therapy following enhanced adherence support: A model of care in Khayelitsha, South Africa. South Af
Med. 2013;14(4):170-176. https://doi.org/10.4102/sajhivmed.v14i4.52

33. Médecins Sans Frontières. Supporting adherence to antiretroviral therapy: A facility approach to reduce the risk of treatment failure [homepage on the Internet]. Report and Toolkit. Cape Town: MSF; 2012. Available from: https:// www.msf.org.za/system/tdf/risk_of_treatment_failure_mentorship_toolkit_v3.p df?file=1\&type=node\&id=3080\&force $=$. Accessed May 26, 2018.

34. Reekiem J, Mocroft A, Ledergerber B, Beniowski M, Clotet B. History of vira suppression on combination antiretroviral therapy as a predictor of virological failure after a treatment change. HIV Med. 2010;10:469-478. https://doi.org/ 10.1111/j.1468-1293.2009.00816.x

35. Smith C, Phillips A, Dauer B, et al. Factors associated with viral rebound among highly treatment-experienced HIV-positive patients who have achieved viral suppression. HIV Med. 2009;10(1):19-27. https://doi.org/10.1111/j.1468-1293. 2008.00650.x

36. Decroo T, Telfer B, Dores CD, et al. Effect of Community ART Groups on retentionin-care among patients on ART in Tete Province, Mozambique: a cohort study. BMJ Open. 2017;7(8):e016800. https://doi,org/10.1136/bmjopen-2017-016800
37. Boender TS, Sigaloff KCE, McMahon JH, et al. Long-term virological outcomes of first-line antiretroviral therapy for HIV-1 in low- and middle-income countries: A systematic review and meta-analysis. Clin Infect Dis. 2015;61(9):1453-1461. A systematic review and meta-an
https://doi.org/10.1093/cid/civ556

38. Murphy R, Sunpath $\mathrm{H}$, Castilla $\mathrm{C}$, et al. Second-line antiretroviral therapy: Longterm outcomes in South Africa. J Acquir Immune Defic Syndr. 2012;61(2):158-163. https://doi.org/10.1097/QAl.0b013e3182615ad1

39. Dang BN, Westbrook RA, Black WC, Rodriguez-Barradas MC, Giordano TP. Examining the link between patient satisfaction and adherence to HIV care: A structural equation model. PLoS One. 2013;8(1):e54729. https://doi.org/10.1371/ journal.pone.0054729

40. O'Connor JL, Gardner EM, Esser S, et al. A simple self-reported adherence tool as a predictor of viral rebound in people with viral suppression on antiretroviral therapy. HIV Med. 2016;17:124-132. https://doi.org/10.1111/hiv.12284

41. Arnsten J, Demas $P$, Farzadegan $\mathrm{H}$, et al. Antiretroviral therapy adherence and vira suppression in HIV-infected drug users: Comparison of self-report and electronic monitoring. Clin Infect Dis. 2001;33(8):1417-1423. https://doi.org/10.1086/ 323201

42. Cambiano V, Lampe F, Rodger A, et al. Use of a prescription-based measure of antiretroviral therapy adherence to predict viral rebound in HIV-infected individuals with viral suppression. HIV Med. 2010;11(3):216-224. https://doi.org/ 10.1111/j.1468-1293.2009.00771.x

43. Liu H, Miller L, Hays R, et al. Repeated measures longitudinal analyses of HIV virologic response as a function of percent adherence, dose timing, genotypi sensitivity, and other factors. J Acquir Immune Defic Syndr. 2006;41(3):315-322. https://doi.org/10.1097/01.qai.0000197071.77482.6e

44. Phillips A, Shroufi A, Vojnov L, et al. Sustainable HIV treatment in Africa through viral-load-informed differentiated care. Nature. 2015;528(7580):S68-S76. https:// doi.org/10.1038/nature16046

45. Manasa J, Katzenstein D, Cassol S, Newell M-L, De Oliveira T. Primary drug resistance in South Africa: Data from 10 years of surveys. AIDS Res Hum Retroviruses. 2012;28(6):558-565. https://doi.org/10.1089/aid.2011.0284

46. Nachega JB, Hislop M, Dowdy DW, Lo M, Regensberg L, Maartens G. Adherence to highly active antiretroviral therapy assessed by pharmacy
claims predicts survival in HIV-infected South African adults. J Acquir Immune Defic Syndr. 2006;43(1):78-84. https://doi.org/10.1097/01.qai.0000225015. Defic Syndr.

47. Johnson V, Cohen K, Wiesner L, et al. Viral suppression following switch to secondline antiretroviral therapy: Associations with nucleoside reverse transcriptase line antiretroviral therapy: Associations with nucleoside reverse transcriptase inhibitor resistance and subtherapeutic drug concentrations prior to
$\mathrm{J}$ Infect Dis. 2014;209 (5):711-720. https://doi.org/10.1093/infdis/jit411

48. Tsegaye A, Wubshet M, Awoke $T$, Alene K. Predictors of treatment failure on second-line antiretroviral therapy among adults in northwest Ethiopia: A multicentre retrospective follow-up study. BMJ Open. 2016;6(12):e0125. https:// doi.org/10.1136/bmjopen-2016-012537 